\title{
Electro-Deposition of Carbon Structures at Mid Voltage and Room Temperature Using Ethanol/Aqueous Solutions
}

Jackson Tsukada, Hudson Zanin, Luiz C. A. Barbosa, Gilmare A. da Silva, Helder J. Ceragioli, Alfredo C. Peterlevitz, Reinaldo F. Teófilo and Vitor Baranauskas

J. Electrochem. Soc. 2012, Volume 159, Issue 3, Pages D159-D161. doi: 10.1149/2.066203jes $\begin{array}{cl}\begin{array}{c}\text { Email alerting } \\ \text { service }\end{array} & \begin{array}{l}\text { Receive free email alerts when new articles cite this article - sign up } \\ \text { in the box at the top right corner of the article or click here }\end{array}\end{array}$

To subscribe to Journal of The Electrochemical Society go to: http://jes.ecsdl.org/subscriptions 


\title{
Electro-Deposition of Carbon Structures at Mid Voltage and Room Temperature Using Ethanol/Aqueous Solutions
}

\author{
Jackson Tsukada, ${ }^{a}$ Hudson Zanin, ${ }^{\text {a,z }}$ Luiz C. A. Barbosa, ${ }^{\text {b }}$ Gilmare A. da Silva, ${ }^{c}$ \\ Helder J. Ceragioli, ${ }^{a}$ Alfredo C. Peterlevitz, ${ }^{a}$ Reinaldo F. Teófilo, ${ }^{b}$ and Vitor Baranauskas ${ }^{a}$ \\ ${ }^{a}$ Departamento de Semicondutores, Instrumentos e Fotônica, Faculdade de Engenharia Elétrica e Computação, \\ Universidade Estadual de Campinas, UNICAMP, Campinas 13083-970, Brazil \\ ${ }^{b}$ Departament of Chemistry, Federal University of Viçosa, Viçosa, MG 36570-000, Brazil \\ ${ }^{c}$ Department of Chemistry, Federal University of Ouro Preto, Ouro Preto, MG 5400-000, Brazil
}

\begin{abstract}
Direct syntheses of carbon structures including nanodiamond, microdiamond and diamond-like carbon (DLC) on silicon wafers by liquid phase electro-deposition are presented. The solution (ethanol/water) was employed as electrolyte at different concentration levels. Assays were carried out maintaining constant the electric potential between the silicon electrodes in the range of ( $80-300 \mathrm{~V})$ at current density of approximately $2.0 \mathrm{~mA} / \mathrm{cm}^{2}$. Scanning electron microscopy showed that non-uniform, smooth and heterogeneous structures were produced. The structural composition was evaluated by micro-Raman spectroscopy. A mechanism for the formation of $\mathrm{sp}^{3}$ and $\mathrm{sp}^{2}$ hybridizations is proposed.

(C) 2012 The Electrochemical Society. [DOI: 10.1149/2.066203jes] All rights reserved.
\end{abstract}

Manuscript submitted November 8, 2011; revised manuscript received December 6, 2011. Published January 6, 2012.

Diamond and carbon related materials have been considered promising materials for many industrial applications due to their superb physicochemical properties such as high hardness, low friction coefficient, wear resistance, high thermal conductivity, chemical inertness, and good biocompatibility, among others. ${ }^{1-4}$ Diamond and carbon related materials have been produced by a variety of chemical vapor deposition techniques (CVD), ${ }^{1,2}$ as well as the low temperature deposition process, such as the electro-deposition. ${ }^{3,4}$

The first attempt to grow carbon films by electro-deposition technique was reported by $\mathrm{Namba}^{5}$ and ever since that, others groups have used such technique for carbon films preparation. ${ }^{3-14}$ Sreejith et al. obtained diamond-like carbon (DLC) at low voltages (80-300 V) and $1 \mathrm{~mm}$ interelectrode separation, which gives electric fields of $0.08-0.3 \mathrm{Vm}^{-1}{ }^{11}$ Graphite and silicon were employed as electrodes (anode/cathode) and ethanol as electrolyte. It is still not clear whether the carbon film deposited had as its source the electrolyte, or the graphite electrode itself or both.

In this work we report the results of our investigation on electrodeposition of carbon films containing nanodiamond and diamond inclusions, diamond-like carbon (DLC) and graphitic phases on silicon wafers, which were submerged in an aqueous ethanol solution. All assays were run at room temperature, without heating or cooling and with a low energy consumption. Raman spectra and scanning electron microscopy images are presented and discussed, and a mechanism for the formation of the $\mathrm{sp}^{3}$ and $\mathrm{sp}^{2}$ hybridization/bonding is proposed.

\section{Experimental}

Mirror polished pieces of $n$-type silicon (100) with resistivity of about $1 \Omega . \mathrm{cm}$ and dimensions of $30 \times 10 \times 0.3 \mathrm{~mm}^{3}$ were used as electrodes (anode and cathode). Prior to deposition process, the silicon substrates were cleaned by ultrasonic treatment in acetone for $30 \mathrm{~min}$. The electrolyte was a solution constituted of analytical grade Merck $^{\circledR}$ ethanol and deionized water. The solution was not agitated during the deposition process. The distance between the electrodes was fixed at $25 \mathrm{~mm}$, the same value for all experiments. The voltage applied between the electrodes was maintained constant during each experiment and ranged from $80 \mathrm{~V}$ to $300 \mathrm{~V}$. Heating or cooling was never applied, so the temperature of the system had a slight increase during the first fifteen minutes, remaining constant until the end of the experiment. In all cases the duration of the experiment was $5 \mathrm{~h}$ and $30 \mathrm{~min}$. and the measured current density was about $2.0 \mathrm{~mA} / \mathrm{cm}^{2}$. Only on the negative electrode was observed the formation of

${ }^{\text {z }}$ E-mail: hudsonzanin@gmail.com dispersed structures. Morphological images were taken using a JSM 5900 LV scanning electron microscope. For chemical analysis a Renishaw ${ }^{\circledR}$ InVia Raman microscope system was used. The micro-Raman measurements were carried out at room temperature employing $785 \mathrm{~nm}$ and $514.5 \mathrm{~nm}$ laser wavelengths. All samples were characterisated by mapping point-by-point micro-Raman scattering.

\section{Results and Discussion}

The electro-deposition cell used an aqueous solution of ethanol as the electrolyte. Table I presents parameters of these depositions. Nanodiamonds, diamonds, DLC and amorphous carbon were directly deposited on silicon wafers without any pre-treatment, except an acetone cleaning process.

Typical scanning electron microscopy images at different magnifications of these as-deposited samples are shown in Figure 1. Images (A) and (B) correspond to sample type (d); images (C) and (D) correspond to sample type (a); image (E) correspond to sample type (c) and image (F) correspond to sample type (b). The deposited structures have no coalescence or uniformity. Some features appears nanocrystalline with cubic grains. Apparently there is no morphological differences between the samples, when they are compared with the same magnifications. To better investigation of these structures, micro-Raman spectroscopy was employed.

Typical Raman spectra of samples, obtained from mapping, with short intervals of point-by-point analysis are depicted in Figure 2. Usually a laser of $514.5 \mathrm{~nm}$ was employed, except for type (a) sample. An intense peak around $1332 \mathrm{~cm}^{-1}$, which corresponds to $\mathrm{sp}^{3}$ carbon hybridization of natural diamond, is present in almost all spectra of Figure 2. The frequency shift ranges from $1325 \mathrm{~cm}^{-1}$ to $1340 \mathrm{~cm}^{-1}$ indicating the presence of some kind of intrinsic or extrinsic stress. ${ }^{15}$ In Figure 2e a peak at $1325 \mathrm{~cm}^{-1}$ is observed and this may be also assigned to a diamond (hexagonal) like structures. ${ }^{16,17}$ Broad bands centered around $1350 \mathrm{~cm}^{-1}$ and $1600 \mathrm{~cm}^{-1}$ correspond to D-band and G-band, respectively. The D-band appears in the range

Table I. Selected parameters of electro-deposited carbon.

$\begin{array}{lccc}\text { Sample Description } & \begin{array}{l}\text { Applied } \\ \text { Potential (V) }\end{array} & \begin{array}{c}\text { Ethanol: Water } \\ (\% \text { v/v })\end{array} \\ \text { Type (a) } & \text { (DLC and Nanodiamond) } & 80 & 98 / 2 \\ \text { Type (b) } & \text { (DLC and Diamond) } & 200 & 98 / 2 \\ \text { Type (c) } & \text { (DLC) } & 300 & 70 / 30 \\ \text { Type (d) } & \text { (Diamond and Graphite) } & 300 & 30 / 70\end{array}$



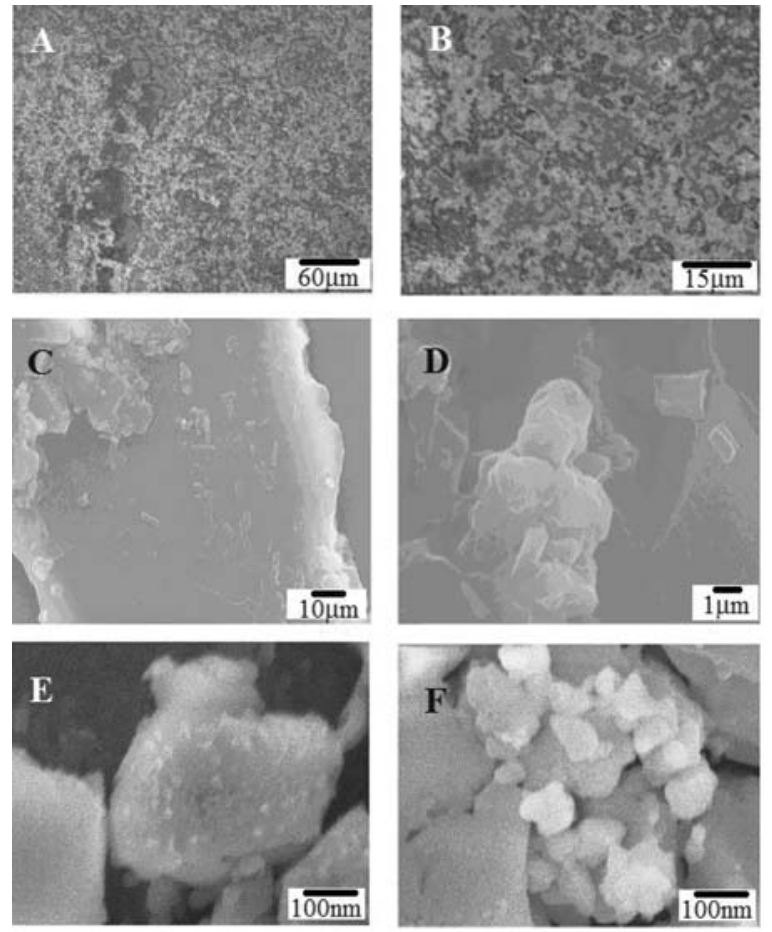

Figure 1. Typical scanning electron microscopy images of as-deposited carbon structures: (A) and (B) correspond to sample type (d), (C) and (D) correspond to sample type (a), and (E) and (F) correspond to type (c) and type (b), respectively.
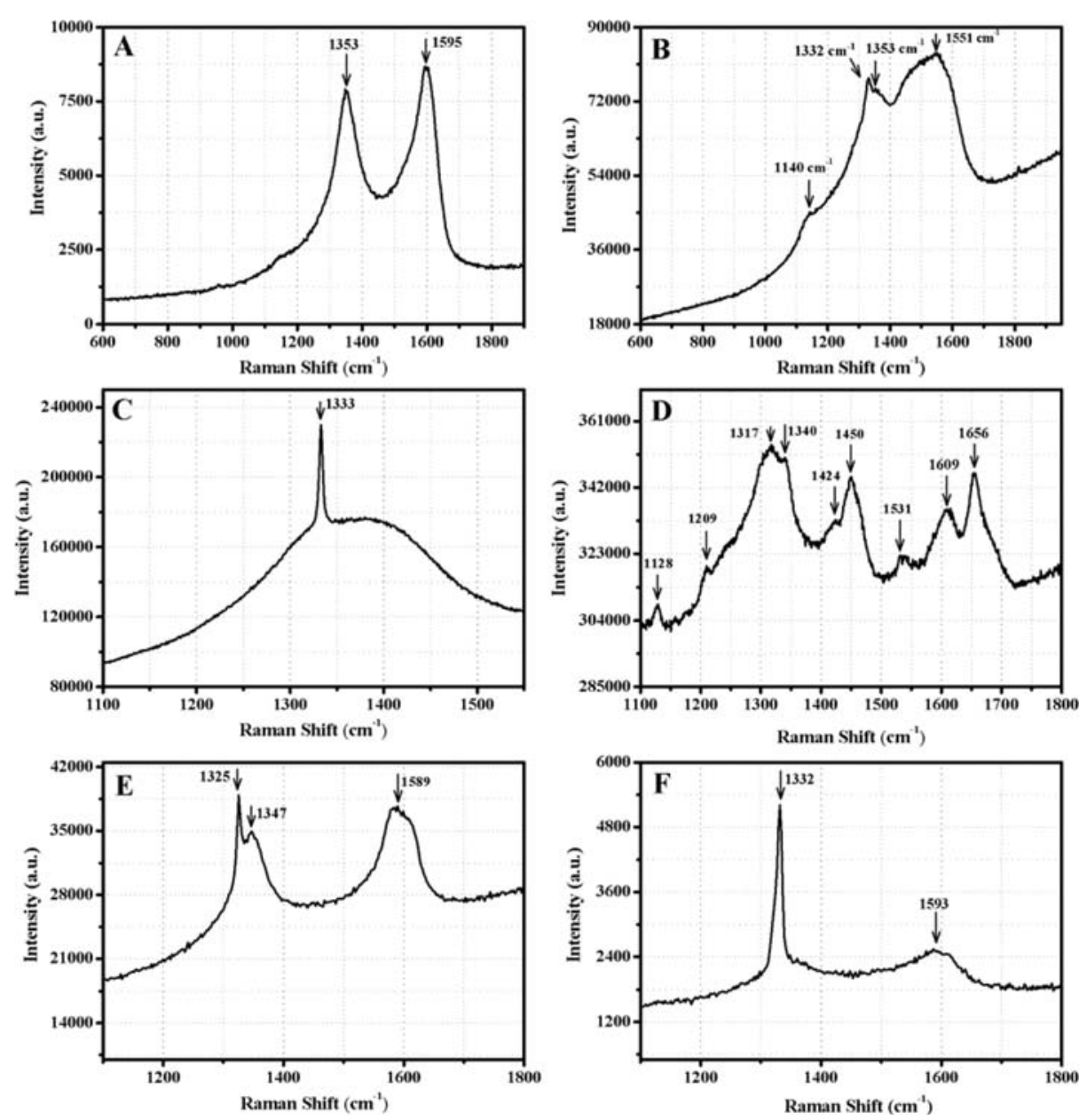

of $1347 \mathrm{~cm}^{-1}$ to $1352 \mathrm{~cm}^{-1}$, is attributed to a disorder-induced mode arising due to zone boundary phonon of $A_{l g}$ symmetry (disordered graphite). ${ }^{12}$ The G-band appears around $1531-1655 \mathrm{~cm}^{-1}$ and is associated with the bond stretching of all pairs of $\mathrm{sp}^{2}$ bonds in both rings and chains, corresponding to the optical zone center phonon of $E_{2 g}$ symmetry, characteristic of graphite type materials. ${ }^{13,14}$ These bands reveal the presence of graphite and amorphous carbon. In Figure $2 \mathrm{c}$ and $2 \mathrm{~d}$ the spectra were obtained using $785 \mathrm{~nm}$ laser excitation which is more sensitive for $\mathrm{sp}^{2}$ carbon hybridization. The Raman shift in these spectra show peaks and broad bands centered at 1128-1140, 1209, 1317-1340, 1347-1352, 1424, 1450, 1531, 1550, 1589-1596, 1609 and $1655 \mathrm{~cm}^{-1}$. The nature of the peak at $1140 \mathrm{~cm}^{-1}$ has been of some controversy since some authors believe that it is associated to nanocrystalline diamond ${ }^{1,18}$ and others attribute this peak to transpolyacetylene ( $\mathrm{sp}^{2}$ carbon) located at grain boundaries, where the polyacetylene would be present ${ }^{18,19}$ Pfeiffer et al. heated at temperatures of $500^{\circ} \mathrm{C}$ and $1200^{\circ} \mathrm{C}$ and concluded that the modes $1150 \mathrm{~cm}^{-1}$ and $1480 \mathrm{~cm}^{-1}$ disappeared. ${ }^{19}$ They assume that these modes originate from short trans-polyacetylene segments since trans-polyacetylene is known to be unstable at high temperatures. Unspecified observed peaks at $1317 \mathrm{~cm}^{-1}$ and $1531 \mathrm{~cm}^{-1}$ would be related to amorphous carbon. P. W. May et al. related peaks in the range of $1459 \mathrm{~cm}^{-1}$ to $1465 \mathrm{~cm}^{-1}$ to trans-polyacetylene. ${ }^{20}$

The results presented in this work have demonstrated that it is possible to deposit a mixture of amorphous carbon, graphite, DLC, microdiamond and nanodiamond on silicon substrates with low voltage and close to room temperature. The structures deposited have been of non-homogeneous films and with low deposition rates, of around $0.1 \mu \mathrm{m} \cdot \mathrm{h}^{-1}$. We believe that the existence of non-uniformity may be related to the growth conditions adopted that still need to be optimized. With better understanding of the deposition mechanism of these materials, it will be find a way to grow homogeneous films
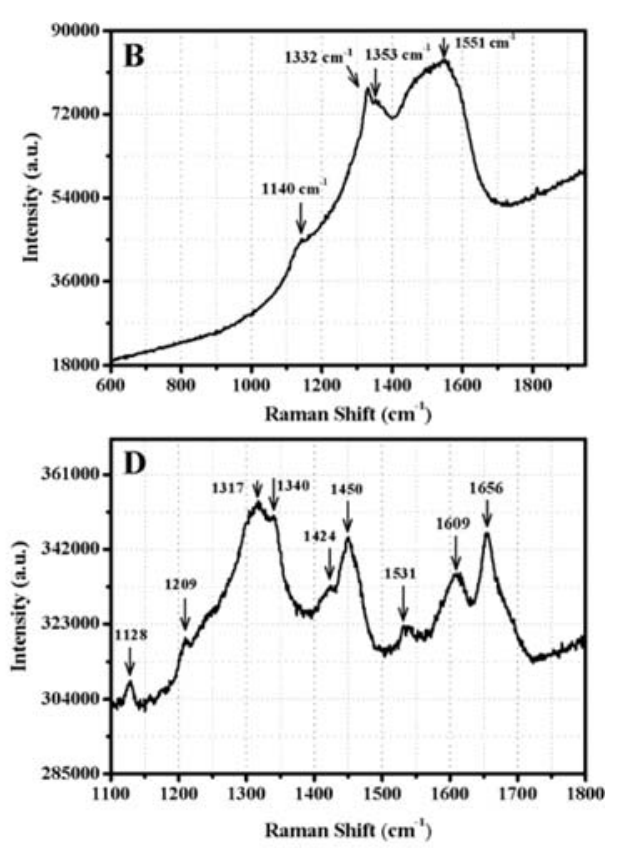

Figure 2. Typical Raman spectra of as-deposited samples: (A) and (B) correspond to the same sample type (a). (C) and (D) correspond to same sample type (b). (E) corresponds to sample type (c). (F) corresponds to sample type (d). For sample type (b) (C and D) a $785 \mathrm{~nm}$ wavelength laser was applied point by point. For images A, B, E and F a $514.5 \mathrm{~nm}$ laser wavelength was employed. 
with uniform composition at temperatures close to the room temperature. The electrolyte plays a very important role in the film growth process. When it consists of deionized water with alcohol, the water interacts in two ways: $(i)$ it can participate in the formation of dynamic hydrogen-bonded chains, thereby raising the polarizability, and; (ii) it can form relatively stable structures such as $\mathrm{H}_{2} \mathrm{O}(\mathrm{ROH})_{4}$ which have zero net dipole moment and consequently diminish volume polarizability, can perhaps help $\mathrm{sp}^{3}$ carbon hybridization in liquid phase electro-deposition technique. ${ }^{21}$

The electro-deposition chemical mechanism of carbon materials is not know, however some mechanisms have been proposed to describe diamond growth. ${ }^{11,14,22-24}$ A mechanism for this process using methanol as organic electrolyte was proposed by $\mathrm{He}$ et al. and Zhu et al. ${ }^{22,24}$ Sreejith et al. showed a mechanism based in ethanol as organic electrolyte. ${ }^{11}$ The mechanism presented in this work is based on empirical observations (presence of trans-polyacetylene), and on the formation of precursor ions and gas products in the solution, as reported by some authors. ${ }^{11,14,22,24}$

Using ethanol as the electrolyte there is a strong possibility that ethanol molecules are polarized under an applied potential, as can be demonstrated by Equation 1:

$$
\mathrm{CH}_{3} \mathrm{CH}_{2}^{\delta+}-\mathrm{OH}^{\delta-} \rightarrow \mathrm{CH}_{3} \mathrm{CH}_{2}^{\delta+} \ldots \mathrm{OH}^{\delta-}
$$

In the cathode (hydrogen-terminated silicon surface), the molecule positive pole is bonded to the $\mathrm{Si}$ surface by replacement of the hydrogen linked to the Si. Further, the ionization of ethanol (loss of $\mathrm{OH})$ occurs by the attacking of hydrogen ion removed over the oxygen bonded to carbon. In the present case, the reaction is given in Equation 2:

$$
\begin{aligned}
& \mathrm{CH}_{3} \mathrm{CH}_{2}^{\delta+} \ldots \mathrm{OH}^{\delta-} \stackrel{\equiv \mathrm{Si}-\mathrm{H}}{\longrightarrow} \mathrm{CH}_{3} \mathrm{CH}_{2 \text { (Solution) }}^{+}+\mathrm{H}_{2} \mathrm{O}+\equiv \mathrm{Si}^{-} \\
& \mathrm{CH}_{3} \mathrm{CH}_{2 \text { (Solution) }}^{+}+\equiv \mathrm{Si}^{-} \rightarrow \equiv \mathrm{Si}-\mathrm{CH}_{2} \mathrm{CH}_{3 \text { (Substrate })}
\end{aligned}
$$

In the cathode (substrate) the major step is the dehydrogenation of ethyl that occurs via electrooxidation reaction (Equation 3):

$$
\mathrm{CH}_{3} \mathrm{CH}_{2}^{+}+n e^{-} \rightarrow 2 \mathrm{C}+5 / 2 \mathrm{H}_{2}
$$

A mechanism that can occur is the coupling of ethyl groups over the substrate. In this case, ethyl ions are inserted into the $\mathrm{C}-\mathrm{H}$ bond elongating the carbon chain (Equation 4). The subsequent dehydrogenation leads to the formation of DLC, diamond or, as presented in the Equation 5, trans-polyacetylene.
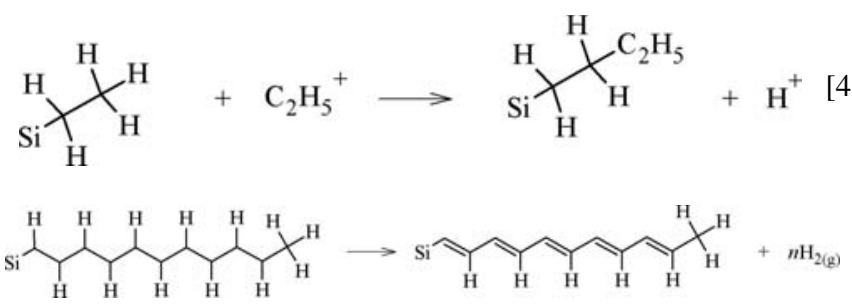

Sreejith et al. propose that bond could also be formed between a carbon and other adjacent carbon on the substrate surface, thus propagating the chain both along the substrate and away from the substrate. ${ }^{11}$
Although the reasonability of this modeling, it should only be regarded as a simplified approximation to the real reaction. A significant observation in the present study is the formation of diamond and diamond-like phases at lower voltages and temperatures compared to the literature values.

\section{Conclusions}

Carbon structures such as nanodiamonds, DLC and amorphous carbon were directly deposited on silicon substrates without any pretreatment. Micro-Raman spectra and scanning electron microscopy showed characteristics of non-uniform materials, besides a small and dense deposited area. This phenomena may be related to the growth conditions and could be optimized in future works. Low temperature electro-depositions are still not consolidated, because the low growth rate and non-uniform formation. Further investigation is required in order to develop an efficient method to deposit more homogeneous films.

\section{Acknowledgments}

The electron microscopy work was performed with the SEM-FEG (JEOL6330F) microscope of the LME/LNLS - Campinas. We also gratefully acknowledge the Brazilian agencies CAPES, FAPESP and $\mathrm{CNPq}$ for financial support.

\section{References}

1. P. W. May, Phil. Trans. R. Soc. A, 358, 473 (2000).

2. R. F. Teófilo, H. J. Ceragioli, A. C. Peterlevitz, L. M. Silva, F. S. Damos, M. M C. Ferreira, V. Baranauskas, and L. T. Kubota, J. Solid State Electrochem., 11, 1449 (2007).

3. H. Wang, M. R. Shen, Z. Y. Ning, C. Ye, H. Y. Dang, C. B. Cao, and H. S. Zhu, Thin Solid Films, 293, 87 (1997).

4. A. H. C. Sirk and D. R. Sadoway, J. Electrochm. Society, 155, 49 (2008).

5. Y. Namba, J. Vac. Sci. Technol., A, 10, 3368 (1992).

6. J. Zhang, L. Huang, L. Yu, and P. Zhang, Appl. Surf. Sci., 258, 3896 (2008).

7. Q. Zeng, G. Dong, and Y. Xie, Appl. Surf. Sci., 254, 2425 (2008).

8. T. M. Manhabosco and I. L. Muller, Appl. Surf. Sci., 255, 4082 (2009).

9. Z. Sun, Y. Sun, and X. Wang, Chem. Phys. lett., 318, 471 (2000).

10. Z. Sun, X. Wang, and Y. Sun, Mater. Sci. Eng. B, 65, 194 (1999).

11. K. Sreejith, J. Nuwad, and C. G. S. Pillai, Appl. Surf. Sci., 252, 296 (2005).

12. D. Guo, K. Cai, L. T. Li, Y. Huang, and Z. L. Gui, Appl. Phys. A, 74, 69 (2002).

13. T. Suzuki, S. Wada, M. Suzuki, T. Yamazaki, and T. Noma, J. Mater. Sci. lett., 19, 1899 (2000)

14. H. Wang, M. R. Shen, Z. Y. Ning, C. Ye, C. B. Cao, H. Y. Dang, and H. S. Zhu, Appl. Phys. lett., 69, 1074 (1996)

15. O. Ternyak, R. Akhvlediani, and A. Hoffman, Diam. Rel. Mater, 14, 323 (2005)

16. V. S. Purohit, D. Jain, V. G. Sathe, V. Ganesan, and S. V. Bhoraskar, J. Phys. D: Appl. Phys., 40, 1794 (2007)

17. S. R. Sails, D. J. Gardiner, M. Bowden, J. Savage, and D. Rodway, Diam. Relat. Mater., 5, 589 (1996). (Monitoring the quality of diamond films using Raman spectra excited at $514.5 \mathrm{~nm}$ and $633 \mathrm{~nm}$ )

18. A. C. Ferrari and J. Robertson, Phys. Rev. B, 63, 121405 (2001).

19. R. Pfeiffer, H. Kuzmany, P. Knoll, S. Bokova, N. Salk, and B. Günther, Diam. Rel. Mater, 12, 268 (2003)

20. P. W. May, J. A. Smith, and K. N. Rosser, Diam. Rel. Mater, 17, 199 (2008).

21. A. D'Aprano, D. I. Donato, and E. Caponetti, J. Sol. Chem., 8, 135 (1979).

22. W. He, R. Yu, H. Wang, and H. Yan, Carbon, 43, 2000 (2005).

23. Q. Fu, J. T. Jiu, C. B. Cao, H. Wang, and H. S. Zhu, Surf. Coat. Technol., 124, 196 (2000).

24. H. S. Zhu, J. T. Jiu, Q. Fu, H. Wang, and C. B. Cao, J. Mater. Sci., 38, 141 (2003). 